\title{
A osteotomia em um plano oblíquo por corte único para correção de deformidades complexas diafisárias de ossos longos: um método para sua realização*
}

\author{
Single-cut oblique plane osteotomy to correct \\ complex diaphyseal deformities of long bones: \\ a method for its performance
}

Ralph Walter Christian ${ }^{1}$, Marcelo Tomanik Mercadante ${ }^{2}$

\section{RESUMO}

A correção das deformidades complexas, aquelas simultaneamente com desvios angular e torcional, é possível por osteogênese e por osteotomias. $O$ presente estudo foi realizado para desenvolver e aplicar um método para a técnica da osteotomia em um plano oblíquo por um único corte, para a correção de deformidades diafisárias complexas em ossos longos (fêmur ou tíbia) e verificar a sua aplicabilidade. Métodos: Este estudo prospectivo envolveu 10 pacientes de ambos os sexos, com idades, entre 17 e 62 anos, que apresentavam deformidades complexas de ossos longos (quatro no fêmur e seis na tíbia) tratados cirurgicamente com osteotomia corretiva pela técnica de corte único em um

* Tese submetida à Faculdade de Ciências Médicas da Santa Casa de São Paulo - obtido o título de Doutor em Ciências da Saúde.

Trabalho aquinhoado com bolsa CAPES.

1. Professor Instrutor, Médico do Grupo do Trauma do Departamento de Ortopedia e Traumatologia da Santa Casa de São Paulo - São Paulo (SP), Brasil.

2. Professor Adjunto, Chefe do Grupo do Trauma do Departamento de Ortopedia e Traumatologia da Santa Casa de São Paulo - São Paulo (SP), Brasil.

Endereço para correspondência: Rua Dr. Cesário Mota Junior, 112, Vila Buarque - 01221-020 - São Paulo (SP), Brasil. Tel.: 21761561. E-mail: trauma@santacasasp.org.br

Recebido em 3/3/08. Aprovado para publicação em 24/9/08.

Copyright RBO2008 plano oblíquo. Os pacientes foram avaliados comparativamente no pré e pós-operatório, para a mensuração das deformidades angulares verdadeiras através do método gráfico, a partir de medições nas radiografias do osso deformado, e clinicalmente para deformidade torcional e do comprimento. Também foram observados o tempo de consolidação e as complicações. O planejamento pré-operatório determinou o cálculo do ângulo do corte do osso. Foram confeccionados para cada paciente um modelo artificial em plástico do osso deformado e nele simulada a correção. Foram realizados desenhos do osso com anotação dos principais passos cirúrgicos e a escolha do local e do tamanho do material de síntese. $O$ planejamento pré-operatório orientou a cirurgia. No pré-operatório, os pacientes apresentavam deformidades com valores médios de: deformidade angular verdadeira de $19^{\circ}$; torção de $12^{\circ}$; encurtamento de $1,3 \mathrm{~cm}$. Resultados: Após correção, as medidas mostraram um valor médio de: deformidade angular verdadeira de $4^{\circ}$ $(p=0,005)$; torção de $1^{\circ}(p=0,005)$ e encurtamento de $0,6 \mathrm{~cm}(\mathbf{p}=0,027)$. Três pacientes apresentaram complicações, sendo dois com retarde de consolidação e outro com infecção profunda tardia e retarde de consolidação. Conclusão: $O$ presente estudo mostrou ser possível estabelecer um método confiável e reprodutível para a técnica da osteoto- 
mia em plano oblíquo por corte único para a correção de deformidades diafisárias complexas de ossos longos.

\footnotetext{
Descritores - Osteotomia/métodos; Diáfises/anormalidades; Estudos prospectivos; Estudos de coortes
}

\section{ABSTRACT}

Correction of complex deformities, those with concomitant angular and torsional deviations, can be done by osteogenesis and by osteotomies. This study was performed to develop and apply a method of single-cut oblique plane osteotomy to correct complex diaphyseal deformities in long bones (femur or tibia) and to check its applicability. Methods: This prospective study involved 10 patients of both genders, ages ranging from 17 to 62, who presented with complex deformities of long bones (four in the femur, six in the tibia) and were surgically treated by corrective osteotomy using the single-cut oblique plane technique. The patients were evaluated comparatively before and after surgery to measure the true angular deformities by a graphic method based on radiographic measurements of the deformed bone, and clinically for the torsional deformity and extension. Time till union and complications were also observed. Pre-operative planning determined the calculation of the bone-cutting angle. For each patient, an artificial model was made of the deformed bone, and the correction was simulated in such model. Drawings of the bone with annotations of the major surgical steps and the choice of the site and size of the synthesis material were made. The pre-operative planning guided the surgery. In the pre-operative stage, the patients had deformities with the following mean values: true angular deformity of $19^{\circ}$; torsion of 12。; shortening of $1.3 \mathrm{~cm}$. Results: After correction, the measurements showed the following mean values: true angular deformity of de $4^{\circ}(p=0.005)$; torsion of $1^{\circ}(p=0.005)$, and shortening of $0.6 \mathrm{~cm}(p=0.027)$. Three patients had complications, two with delayed union, and one with late deep infection and delayed union. Conclusion: This study showed that it is possible to set up a reliable and reproducible method for the single-cut oblique plane osteotomy technique to correct complex diaphyseal deformities of long bones.

\section{Keywords - Osteotomy/methods; Diaphyses/ abnormalities; Prospective studies; Cohort studies}

\section{INTRODUÇÃO}

As deformidades dos ossos longos são complexas quando coexistem componentes torcionais e angulares $^{(1)}$. Estas deformidades podem ser corrigidas por osteogênese e por osteotomias. As osteotomias com subtração de cunha óssea agregam encurtamento ósseo, enquanto que as por adição necessitam enxerto ósseo a ser retirado de área doadora. As cupuliformes, usadas freqüentemente nas correções das deformidades metafisárias, são de difícil execução na região diafisária. Todas determinam área de contato limitada, o que pode dificultar a estabilização com osteossíntese interna e prolongar o tempo para consolidação.

$\mathrm{O}$ método de osteogênese necessita do emprego por tempo prolongado de fixador externo, mas tem a vantagem de possibilitar correção simultaneamente de encurtamento e de desvio torcional e angular. A osteotomia única em plano oblíquo é capaz de corrigir a deformidade complexa sem necessidade de adição ou subtração de cunha óssea e produz superfícies de corte planas, com boa adaptação entre os fragmentos, sendo compatível com a fixação interna imediata, dispensando enxerto ósseo. Quando necessário, o deslizamento longitudinal da superfície óssea do corte oblíquo permite ganho de comprimento.

A literatura apresenta descrições antigas da técnica de osteotomia em plano oblíquo ${ }^{(2)}$ e que foram aperfeiçoadas $^{(1,3-5)}$. Ressaltamos dois trabalhos publicados em nosso meio: Rossi et al $^{(4)}$ e Paccola ${ }^{(6)}$. Trabalhos há que são ilustrados com exemplos de modelos para planejamento pré-operatório ${ }^{(6-7)}$, e outros com casos clínicos ${ }^{(5,8)}$. Aspectos técnicos e práticos do planejamento e da execução cirúrgica foram pouco detalhados.

Este trabalho apresenta um método para a técnica da osteotomia em plano oblíquo com corte único em 
ossos longos com deformidades complexas pós-traumáticas diafisárias descrevendo os resultados de uma série de 10 pacientes tratados.

A técnica empregada e o necessário planejamento da osteotomia em plano oblíquo foram apresentados por Sangeorzan et al e são baseados em complexo modelo matemático do qual resultam diagramas ou tabelas usadas para determinar o ângulo da inclinação da osteotomia oblíqua ${ }^{(1)}$.

É necessário o reconhecimento da deformidade angular verdadeira e da deformidade torcional para a determinação do ângulo de inclinação do plano do corte ósseo capaz de corrigir a angulação e torção simultaneamente.

Uma deformidade angular pode existir em qualquer plano. Ao avaliarmos radiografias em ântero-posterior (AP) e perfil (P), precisamos compreender que não existe a deformidade em cada plano, mas sim uma deformidade angular que é única, cujas projeções são observadas nas radiografias convencionais. A angulação existente é maior que os valores mensurados nas projeções radiográficas e está contida em um outro plano situado entre os planos ortogonais de referência.

Existem dois métodos para determinar a deformidade verdadeira a partir de valores das deformidades medidas nas projeções AP e P: o trigonométrico, mais preciso, porém complicado ${ }^{(1,9)}$, e um método gráfico, simplificado $^{(5-6,9)}$. Neste ultimo é usado um sistema de eixos ortogonais $\mathbf{X}$ e $\mathbf{Y}$ e o valor angular medido nas projeções AP e P são transformados proporcionalmente em medidas lineares (por exemplo, $1^{\circ}=0,5 \mathrm{~cm}$ ). Insere-se o valor em graus da deformidade na incidência AP, transformado em valor linear no eixo X. Analogamente, o valor angular medido no perfil é transformado em linear e anotado no eixo Y. Estabelecidos os comprimentos das coordenadas de nosso gráfico, encontramos o ponto de interseção de suas perpendiculares. O comprimento da reta entre este ponto e o ponto de origem do sistema, transformado na mesma proporção linear para graus, determina a angulação da deformidade verdadeira.

Tomemos como exemplo uma deformidade da tíbia com valores de angulações da deformidade medidos nas projeções $\mathbf{A P}$ de $26^{\circ}$ e na projeção $\mathbf{P}$ de 36 graus.
Inserimos o valor de 26 no eixo AP e o valor de 36 no eixo P. Em continuidade, traçamos a reta que vai da origem do gráfico, até o ponto de interseção das coordenadas. Traçada a reta entre esses pontos, teremos de maneira indireta o valor do ângulo verdadeiro da deformidade, que está expresso no comprimento da reta obtida, desde que convertida pela mesma escala inicialmente estabelecida (neste caso, $1^{\circ}$ igual a $0,5 \mathrm{~cm}$ ). Esse ângulo é chamado de ângulo Alfa $(\alpha)$, e no nosso exemplo resulta em $45^{\circ}$ (figura 1 ).

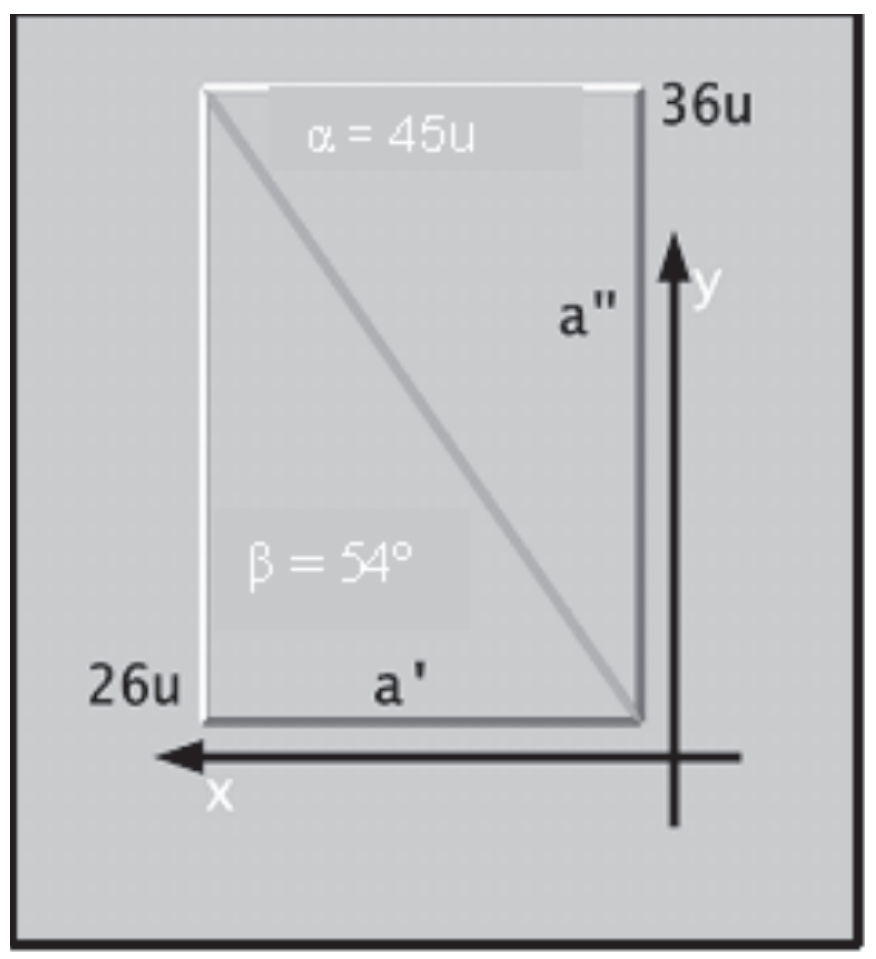

Figura 1 - Sistema de coordenadas, onde no eixo $X$ é inserida a projeção $\operatorname{AP}\left(a^{\prime}\right)$ e no eixo $Y$ inserida a projeção do $P\left(a^{\prime \prime}\right)$ determinando a reta cujo comprimento equivale à deformidade verdadeira (ângulo $\alpha$ ). $O$ ângulo entre a abscissa AP e a reta que determina a deformidade verdadeira (ângulo $\beta$ ) que localiza o plano que contém a deformidade.

O ângulo entre uma coordenada (ordenada ou abscissa, que são complementares) e esta reta é o ângulo que determina a posição do plano que contém a deformidade angular verdadeira (ângulo Beta $[\beta]$ ) a partir do plano P (ordenada) ou AP (abscissa). Em nosso exemplo, o ângulo $\beta$ é de $54^{\circ}$.

Determinado o valor da deformidade angular verdadeira, necessitamos conhecer o valor da deformida- 
de torcional. Esta pode ser medida clinicamente ${ }^{(3,8,10)}$ ou por radiografias, ultra-som ou tomografias, sendo esta última a mais precisa ${ }^{(5-6,11-13)}$.

Conhecidos os três valores, ângulo $\alpha$ de deformidade angular verdadeira, ângulo $\beta$ de localização do plano que contém a deformidade verdadeira e o ângulo " $t$ " da torção, e empregando o diagrama de Sangeor$\operatorname{zan}^{(1)}$, obtemos o ângulo de inclinação do corte da osteotomia em relação à perpendicular do eixo do segmento distal do osso diafisário deformado (ângulo Teta) (figura 2).

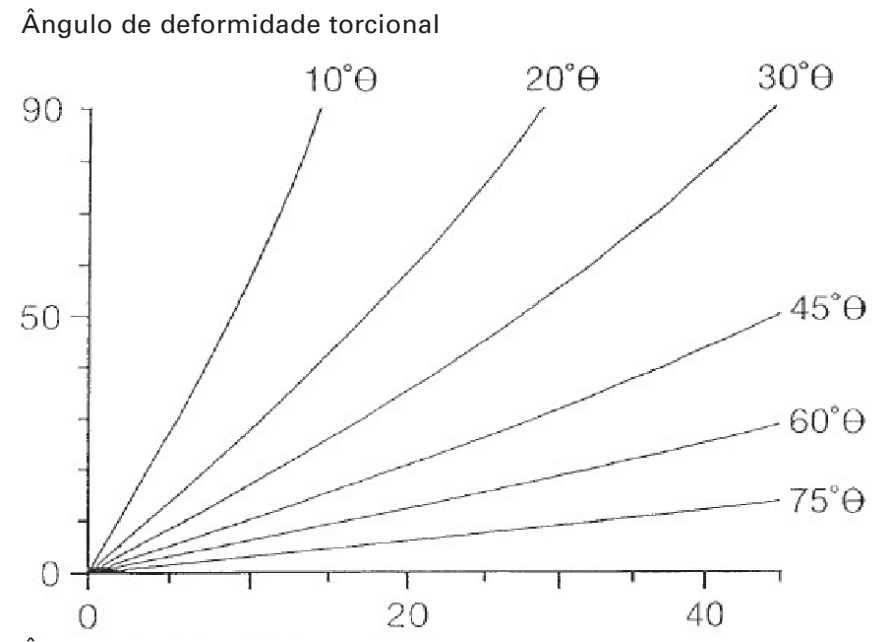

Ângulo de deformidade verdadeira

Figura 2 - Diagrama de Sangeorzan ${ }^{(4)}$

\section{MÉTODOS}

\section{Casuística}

Este trabalho prospectivo foi baseado no tratamento de 10 pacientes de ambos os sexos, idade entre 17-62 anos, com deformidades complexas dos ossos longos (quatro acometendo o fêmur e seis a tíbia).

Incluímos pacientes com esqueleto maduro, portadores de deformidades pós-traumáticas, com desvio angular uniapical, associado a desvio torcional, sendo ao menos um deles maior do que $10^{\circ}$. Excluímos aqueles pacientes com sinais de infecção óssea aguda ou crônica e os pacientes em que cirurgias ortopédicas de grande porte estavam contra-indicadas. $\mathrm{O}$ estudo foi aprovado pelo Comitê de Ética em Pesquisas da Irmandade da Santa Casa de Misericórdia de São Paulo sob o número 308/04.

\section{Método}

O método desenvolvido para a correção das deformidades complexas por osteotomia única em plano oblíquo requer avaliação e planejamento individualizado para cada paciente.

Fase pré-operatória-Avaliamos clinicamente o paciente e realizamos os exames radiográficos do segmento em AP e P (quadro 1).

No exame físico reconhecemos pelo método clínico a existência das deformidades angular e torcional do fêmur ${ }^{(13)}$ e da tíbia ${ }^{(14)}$. A mensuração longitudinal do membro foi realizada com fita métrica de forma habitual, tomando como parâmetros sempre pontos de referência ósseos, optando pelos mais adequados para cada caso clínico.

Os exames subsidiários de imagem realizados são as radiografias em ântero-posterior e perfil do segmento do esqueleto apendicular afetado, incluindo as articulações adjacentes, e radiografia panorâmica dos membros inferiores na incidência ântero-posterior em pé, compensando a dismetria, o que permite antever o resultado, sem correção, que estamos buscando.

Planejamento pré-operatório - A partir dos dados colhidos na evolução do paciente e suas radiografias é determinado o ângulo verdadeiro da deformidade, pelo método gráfico (quadro 2).

Construímos um modelo idêntico ao osso deformado, em molde artificial a partir de um osso plástico $\left(\right.$ Synbone $\left.^{\circledR}\right)$. Obtido os valores angulares da deformidade conforme a técnica já descrita, podemos determinar a localização e orientação precisa desta no osso longo. Realizamos a secção do modelo, buscando o ponto correspondente à deformidade do osso do paciente. Os fragmentos foram colados com massa de resina epóxi, reproduzindo a deformidade do paciente, baseado nos dados numéricos. Para manter a posição dos fragmentos do modelo durante a secagem da resina, foi introduzido um tubo de cobre ou alumínio na "região intramedular" do modelo em plástico, sendo modelado na intensidade conveniente.

O ângulo da deformidade verdadeira (ângulo $\alpha$ ) e o ângulo da deformidade torcional (ângulo $\theta$ ) foram aplicados ao diagrama de Sangeorzan, que por leitura 
QUADRO 1

Dados sociodemográficos e da anamnese

\begin{tabular}{|c|c|c|c|c|c|c|c|c|c|}
\hline $\mathbf{N}$ & $\begin{array}{c}\mathrm{N} / \\
\text { Iniciais }\end{array}$ & RG & $\begin{array}{l}\text { Idade } \\
\text { (anos) }\end{array}$ & Sexo & Profissão & Osso & Lado & Acidente & $\begin{array}{c}\text { Tempo de } \\
\text { existência da } \\
\text { deformidade } \\
\text { (meses) }\end{array}$ \\
\hline 1 & S.S.F. & 757732 & 17 & M & estudante & fêmur & $\mathrm{D}$ & trânsito (auto) & 60 \\
\hline 2 & E.H. & 919235 & 27 & M & eletricista & tíbia & D & trânsito (moto) & 11 \\
\hline 3 & J.A.C. & 920463 & 62 & $\mathrm{~F}$ & $\begin{array}{c}\text { trabalhadora } \\
\text { rural }\end{array}$ & fêmur & E & $\begin{array}{c}\text { queda da } \\
\text { própria altura) }\end{array}$ & 36 \\
\hline 4 & E.L.S. & 899559 & 48 & M & pintor & tíbia & E & $\begin{array}{l}\text { trânsito (queda } \\
\text { de caçamba) }\end{array}$ & 240 \\
\hline 5 & R.A.A.C. & 893777 & 32 & $\mathrm{M}$ & $\begin{array}{l}\text { auxiliar } \\
\text { geral }\end{array}$ & fêmur & E & $\begin{array}{c}\text { trânsito } \\
\text { (atropelamento) }\end{array}$ & 36 \\
\hline 6 & C.T.M. & 979054 & 33 & M & cabeleireiro & fêmur & $E$ & trânsito (auto) & 12 \\
\hline 7 & L.M.S. & 986994 & 30 & $M$ & ajudante & tíbia & E & $\begin{array}{c}\text { trânsito } \\
\text { (atropelamento) }\end{array}$ & 108 \\
\hline 8 & A.P.R. & 1006111 & 44 & $M$ & vigilante & tíbia & $\mathrm{D}$ & trânsito (moto) & 84 \\
\hline 9 & D.C.C.S. & 951121 & 29 & $\mathrm{~F}$ & vendedora & tíbia & $\mathrm{D}$ & trânsito (moto) & 27 \\
\hline 10 & J.O.S. & 1009035 & 21 & M & $\begin{array}{l}\text { ajudante } \\
\text { de obras }\end{array}$ & tíbia & $E$ & esporte (futebol) & 8 \\
\hline
\end{tabular}

direta permite determinar o ângulo de inclinação do corte único de osteotomia. Esse ângulo é chamado de "Teta".

No modelo ósseo em plástico, com a deformidade complexa similar a do paciente, posicionamos um fio de Kirschner (K1) de 2,5mm de diâmetro na região da deformidade, orientado a $90^{\circ} \mathrm{com}$ o eixo longitudinal do segmento distal, no plano coronal. Usando a técnica de avaliação pela visão sem deformidade, vamos realizando a rotação do modelo, até o ângulo de visão em que não percebemos a deformidade ${ }^{(7)}$. Esse é o ponto do ápice da deformidade, local onde é posicionado o segundo fio de Kirschner (K2) de mesmo calibre, a $90^{\circ}$ com o eixo longitudinal do segmento distal.

Neste momento o modelo matemático de Sangeorzan apresenta duas soluções possíveis, isto é, o ângulo teta medido a partir do fio K1 para um lado ou para outro, significando que o traço da osteotomia poderá ser realizado de proximal para distal, ou ao contrário $^{(1)}$. Embora pareça pouco importante, é a direção da osteotomia que irá determinar o sentido da correção da rotação, para interno ou externo, ao deslizar os fragmentos pelo traço da osteotomia (figura 3 ).

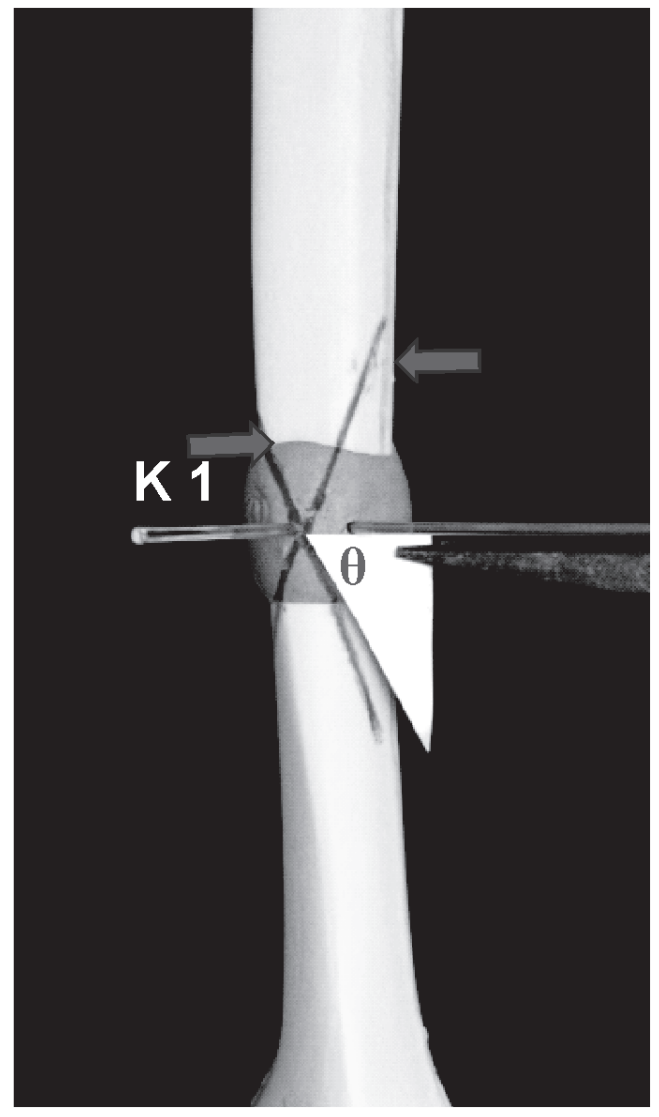

Figura 3 - Modelo artificial do osso deformado, com os fios $\mathrm{K} 1$ e K2 inseridos, e a indicação das duas possibilidades do corte da osteotomia (setas vermeIhas) a partir do ângulo Teta indicado com molde metálico. 
QUADRO 2

Dados relativos às lesões e mensurações das deformidades pré-operatórias

\begin{tabular}{|c|c|c|c|c|c|c|c|c|}
\hline $\mathbf{N}$ & $\begin{array}{c}\text { Osso/ } \\
\text { tipo de } \\
\text { fratura }\end{array}$ & $\begin{array}{l}\text { Outras } \\
\text { lesões }\end{array}$ & $\begin{array}{c}\text { Tratamento } \\
\text { da fratura }\end{array}$ & Def. AP & Def. $P$ & $\begin{array}{c}\text { Def. } \\
\text { torcional }\end{array}$ & $\begin{array}{l}\text { Def. } \\
\text { verd }\end{array}$ & $\begin{array}{c}\text { Ângulo } \\
\text { plano } \\
\text { AP }\end{array}$ \\
\hline 1 & $\begin{array}{c}\text { fêmur } \\
\text { fechada }\end{array}$ & $\begin{array}{c}\text { joelho } \\
\text { flutuante } \\
\text { tíbia }\end{array}$ & $\begin{array}{c}\text { tração } \\
\text { esquelética } \\
\text { mais GPP }\end{array}$ & $\begin{array}{c}21^{\circ} \\
\text { varo }\end{array}$ & $\begin{array}{l}20^{\circ} \\
\text { recurvo }\end{array}$ & $\begin{array}{l}10^{\circ} \\
\text { rot. ext. }\end{array}$ & $29^{\circ}$ & $\begin{array}{c}45^{\circ} \\
\left(135^{\circ}\right)\end{array}$ \\
\hline 2 & $\begin{array}{c}\text { tíbia } \\
\text { exposta }\end{array}$ & - & $\begin{array}{c}\text { fixador } \\
\text { externo } \\
\text { gesso PTB }\end{array}$ & $\begin{array}{c}10^{\circ} \\
\text { valgo }\end{array}$ & $\begin{array}{c}12^{\circ} \\
\text { antecurvo }\end{array}$ & $\begin{array}{l}10^{\circ} \\
\text { rot. ext. }\end{array}$ & $16^{\circ}$ & $\begin{array}{c}51^{\circ} \\
\left(309^{\circ}\right)\end{array}$ \\
\hline 3 & $\begin{array}{c}\text { fêmur } \\
\text { fechada }\end{array}$ & - & $\begin{array}{l}\text { osteossíntese } \\
\text { interna } \\
\text { com DCS }\end{array}$ & $\begin{array}{c}26^{\circ} \\
\text { varo }\end{array}$ & $\begin{array}{c}28^{\circ} \\
\text { antecurvo }\end{array}$ & $\begin{array}{l}12^{\circ} \\
\text { rot. ext. }\end{array}$ & $38^{\circ}$ & $\begin{array}{c}46^{\circ} \\
\left(314^{\circ}\right)\end{array}$ \\
\hline 4 & $\begin{array}{c}\text { tíbia } \\
\text { fechada }\end{array}$ & $\begin{array}{l}\text { joelho } \\
\text { flutuante } \\
\text { fêmur } \\
\text { fechada }\end{array}$ & gesso na tíbia & $\begin{array}{c}12^{\circ} \\
\text { valgo }\end{array}$ & $\begin{array}{c}16^{\circ} \\
\text { antecurvo }\end{array}$ & $\begin{array}{l}10^{\circ} \\
\text { rot. ext. }\end{array}$ & $20^{\circ}$ & $\begin{array}{c}52^{\circ} \\
\left(232^{\circ}\right)\end{array}$ \\
\hline 5 & $\begin{array}{c}\text { fêmur } \\
\text { fechada }\end{array}$ & - & $\begin{array}{l}\text { placa DHS } \\
\text { longa em } \\
\text { ponte }\end{array}$ & $\begin{array}{c}10^{\circ} \\
\text { valgo }\end{array}$ & $\begin{array}{c}12^{\circ} \\
\text { antecurvo }\end{array}$ & $\begin{array}{l}20^{\circ} \\
\text { rot. ext. }\end{array}$ & $16^{\circ}$ & $\begin{array}{c}51^{\circ} \\
\left(231^{\circ}\right)\end{array}$ \\
\hline 6 & $\begin{array}{c}\text { fêmur } \\
\text { fechada }\end{array}$ & $\begin{array}{c}\text { tíbia } \\
\text { contralateral } \\
\text { + clavícula E }\end{array}$ & $\begin{array}{c}\text { tração + } \\
\text { haste } \\
\text { intramedular } \\
\text { Ender }\end{array}$ & $\begin{array}{c}5^{\circ} \\
\text { varo }\end{array}$ & $0^{\circ}$ & $\begin{array}{l}16^{\circ} \\
\text { rot. ext. }\end{array}$ & $5^{\circ}$ & $0^{\circ}$ \\
\hline 7 & $\begin{array}{c}\text { tíbia } \\
\text { fechada }\end{array}$ & - & $\begin{array}{c}\text { gesso } \\
\text { cruropodálico }\end{array}$ & $\begin{array}{c}26^{\circ} \\
\text { varo }\end{array}$ & $\begin{array}{c}8^{\circ} \\
\text { antecurvo }\end{array}$ & $\begin{array}{l}15^{\circ} \\
\text { rot. int. }\end{array}$ & $27^{\circ}$ & $\begin{array}{c}17^{\circ} \\
\left(343^{\circ}\right)\end{array}$ \\
\hline 8 & $\begin{array}{c}\text { tíbia } \\
\text { exposta }\end{array}$ & - & $\begin{array}{l}\text { fixador } \\
\text { externo } \\
\text { linear }\end{array}$ & $\begin{array}{c}14^{\circ} \\
\text { valgo }\end{array}$ & $\begin{array}{c}8^{\circ} \\
\text { recurvo }\end{array}$ & $\begin{array}{l}12^{\circ} \\
\text { rot. int. }\end{array}$ & $16^{\circ}$ & $\begin{array}{c}30^{\circ} \\
\left(30^{\circ}\right)\end{array}$ \\
\hline 9 & $\begin{array}{c}\text { tíbia } \\
\text { exposta }\end{array}$ & $\begin{array}{l}\text { joelho } \\
\text { flutuante } \\
\text { fêmur }\end{array}$ & $\begin{array}{c}\text { fixador } \\
\text { externo } \\
\text { linear }\end{array}$ & $\begin{array}{c}12^{\circ} \\
\text { varo }\end{array}$ & $\begin{array}{c}8^{\circ} \\
\text { recurvo }\end{array}$ & $\begin{array}{l}8^{\circ} \\
\text { rot. int. }\end{array}$ & $14^{\circ}$ & $\begin{array}{c}34^{\circ} \\
\left(146^{\circ}\right)\end{array}$ \\
\hline 10 & $\begin{array}{c}\text { tíbia } \\
\text { fechada }\end{array}$ & - & $\begin{array}{c}\text { gesso } \\
\text { cruropodálico } \\
\text { PTB e órtese }\end{array}$ & $\begin{array}{l}12^{\circ} \\
\text { varo }\end{array}$ & $\begin{array}{c}5^{\circ} \\
\text { recurvo }\end{array}$ & $\begin{array}{l}8^{\circ} \\
\text { rot. int. }\end{array}$ & $13^{\circ}$ & $\begin{array}{l}23^{\circ} \\
\left(23^{\circ}\right)\end{array}$ \\
\hline
\end{tabular}

Utilizando uma serra de metal, realizamos a "osteotomia" do modelo ósseo com um corte paralelo ao fio K2, com a inclinação em relação ao plano transversal do fragmento distal indicada pelo fio K1, formando o ângulo do corte com o valor obtido no diagrama de Sangeorzan (ângulo Teta).

A verificação da correção é testada, deslizando o fragmento distal até a correção da deformidade angular. Observamos o sentido da rotação do fragmento, e verifica-se o ocorrido. São duas as possibilidades: a correção da rotação ou o aumento da deformidade ro- tacional. Isso é verificado porque são duas as soluções possíveis para esse modelo matemático, e não se consegue estabelecer previamente a direção do ângulo de corte em relação ao plano transversal. Quando a correção não acontecia, indicava orientação errada do corte. Nesta eventualidade, outro modelo foi preparado e o corte realizado na orientação contrária, sendo comparada a correção rotacional.

O passo seguinte é realizar desenhos do planejamento cirúrgico, a partir de radiografias do osso afetado e radiografias invertidas do osso contralateral ${ }^{(11)}$. Nos 
desenhos mostrando o osso deformado e com a deformidade corrigida é determinado o ponto exato da osteotomia, sua orientação, o comprimento do corte, tamanho da placa e dos parafusos para a osteossíntese, conforme a técnica preconizada pela $\mathrm{AO}^{(15-16)}$.

Fase cirúrgica - Todos os 10 pacientes foram submetidos à raquianestesia e posicionados em mesa cirúrgica comum, com tampo radiotransparente. Nas cirurgias dos fêmures foram realizados acesso cirúrgico lateral, retrovastos, e para as tíbias, acessos ânterolateral ou ântero-medial, dependendo da posição do ápice da deformidade. Sempre realizamos osteotomias das fíbulas nas pernas operadas.

Após expor o ápice e a concavidade da deformidade óssea $^{(7)}$, utilizamos a radioscopia para identificar a imagem sem deformidade. Nesse momento são introduzidos os fios K1 e K2 de maneira análoga à empregada no modelo. Os fios são posicionados com auxílio de radioscopia e de um guia metálico de $90^{\circ}$ (utilizamos o existente no material para placas anguladas da AO). A partir do fio K1 marcamos o ângulo (Teta) entre o plano transversal (K1) e o ápice da deformidade (K2). A magnitude do ângulo Teta, conhecida no diagrama de Sangeorzan, foi reproduzida em um guia metálico confeccionado a partir de lata de alumínio, esterilizado, e neste momento aposto ao osso, permitindo assim a demarcação da linha de corte da osteotomia.

Levamos em todas as oportunidades o modelo de plástico para a sala cirúrgica e, nesse momento, comparamos os traços realizados no modelo com o marcado no paciente. Realizamos o corte com serra óssea oscilante pneumática, tendo como guias a ângulo metálico e o paralelismo com o fio K2. Foi muito útil transfixar as corticais ósseas com o fio de Kirschner, para este servir de eixo de orientação do corte, evitando desvios laterais da lâmina da serra durante o corte. A seguir, ao deslizar o fragmento distal no sentido da correção da deformidade angular, há simultaneamente a correção da deformidade torcional. Seguimos realizando o alinhamento e estabilização temporária com pinças de redução, e a osteossíntese interna com parafuso de tração pelo traço de osteotomia, habitualmente longo, e placa dynamic compression plate (DCP) de neutralização. Nos pacientes em que coexistia encurtamento ósseo, realizamos o deslizamento longitudinal do fragmento distal por tração manual, objetivando ganhar o comprimento necessário.

Fase pós-operatória - Os pacientes foram acompanhados durante o pós-operatório imediato internados, quando nossa atenção voltou-se para o acompanhamento clínico da ferida cirúrgica, buscando sinais das complicações, e assistência fisioterápica, iniciando a mobilização passiva e ativa assistida. Habitualmente, entre o quinto e sétimo dia pós-operatório, foi possível a alta hospitalar e acompanhamento ambulatorial, quinzenal no primeiro mês e mensal depois deste. Novas mensurações clínicas buscando deformidade residual e radiografias foram realizadas. Repetindo o método gráfico, buscamos identificar deformidade angular ou de comprimento residual verdadeira nos exames subsidiários (quadros 3 e 4).

\section{RESULTADOS}

O grupo de pacientes por nós avaliados tinha em média de 34,3 anos (17-62 anos) e adquirido suas deformidades, ou seja, as fraturas dadas por consolidadas, em média há 62,2 meses (1-240 meses). A deformidade angular verdadeira pré-operatória média era de $19^{\circ}\left(5^{\circ}-38^{\circ}\right)$ e o desvio rotacional médio de $12^{\circ}\left(8^{\circ}-\right.$ $\left.20^{\circ}\right)$. O encurtamento pré-operatório médio medido era de $1,3 \mathrm{~cm}$, com valores de encurtamento variando entre 0 e $3 \mathrm{~cm}$.

A avaliação pós-operatória mostrou correção da deformidade angular para valor médio de $4^{\circ}\left(0^{\circ}-10^{\circ}\right)$ e correção da deformidade torcional para média de $1^{\circ}$ $\left(0^{\circ}-3^{\circ}\right)$. O comprimento corrigido foi em média de $0,6 \mathrm{~cm}$, com valores de encurtamento entre 0 e $2,5 \mathrm{~cm}$.

As avaliações pré-operatórias foram comparados em cada paciente com os resultados pós-operatórios quanto à deformidade angular verdadeira, à deformidade torcional e ao encurtamento. Um paciente apresentou deformidade angular verdadeira residual acima de $5^{\circ}$, situado no plano sagital. Este paciente sofreu queda no pós-operatório e necessitou de reoperação, com nova osteossíntese. Evoluiu com retarde da consolidação e infecção profunda, necessitando limpezas cirúrgicas. Outro paciente apresentou deformidade residual em 
QUADRO 3

Dados relativos aos procedimentos cirúrgicos e pós-operatórios

\begin{tabular}{|c|c|c|c|c|c|c|c|c|c|}
\hline \multirow[t]{2}{*}{$\mathbf{N}$} & \multirow{2}{*}{$\begin{array}{l}\text { Ângulo } \\
\text { corte }\end{array}$} & \multirow{2}{*}{$\begin{array}{c}\text { Data } \\
\text { da cirurgia }\end{array}$} & \multirow{2}{*}{$\begin{array}{l}\text { Via de } \\
\text { acesso }\end{array}$} & \multicolumn{2}{|c|}{ Síntese } & \multicolumn{3}{|c|}{ Deformidade } & \multirow{2}{*}{$\begin{array}{c}\text { Ângulo } \\
\text { verdadeiro }\end{array}$} \\
\hline & & & & Placa & Parafuso & AP & $\mathbf{P}$ & Rotacional & \\
\hline 1 & $75^{\circ}$ & 09/05/2002 & $\begin{array}{c}\text { Retro } \\
\text { vasto } \\
\text { lateral }\end{array}$ & $\begin{array}{c}\text { DCP } \\
\text { larga } \\
14 \text { furos }\end{array}$ & 2 & $0^{\circ}$ & $0^{\circ}$ & $0^{\circ}$ & $0^{\circ}$ \\
\hline 2 & $60^{\circ}$ & $18 / 02 / 2004$ & $\begin{array}{l}\text { Ântero } \\
\text { lateral }\end{array}$ & $\begin{array}{c}\text { DCP } \\
\text { larga } \\
9 \text { furos }\end{array}$ & 1 & $0^{\circ}$ & $2^{\circ}$ antecurvo & $3^{\circ}$ interno & $2^{\circ}$ \\
\hline 3 & $75^{\circ}$ & 09/06/2004 & $\begin{array}{l}\text { Lateral } \\
\text { distal }\end{array}$ & $\begin{array}{c}\text { DCP } \\
\text { larga } \\
10 \text { furos }\end{array}$ & 2 & $3^{\circ}$ valgo & $0^{\circ}$ & $0^{\circ}$ & $3^{\circ}$ \\
\hline 4 & $66^{\circ}$ & $23 / 06 / 2004$ & $\begin{array}{l}\text { Ântero } \\
\text { lateral }\end{array}$ & $\begin{array}{c}\text { DCP } \\
9 \text { furos }\end{array}$ & 2 & $0^{\circ}$ & $3^{\circ}$ recurvo & $0^{\circ}$ & $3^{\circ}$ \\
\hline 5 & $41^{\circ}$ & $\begin{array}{l}\text { 1) } 22 / 03 / 2005 \\
\text { 2의 } 04 / 05 / 2005\end{array}$ & Lateral & $\begin{array}{c}\text { DCP } \\
\text { larga } \\
14 \text { furos }\end{array}$ & 1 & $0^{\circ}$ & $10^{\circ}$ antecurvo & $0^{\circ}$ & $10^{\circ}$ \\
\hline 6 & $19^{\circ}$ & $11 / 05 / 2005$ & $\begin{array}{c}\text { Retro } \\
\text { vasto } \\
\text { lateral }\end{array}$ & $\begin{array}{c}\text { DCP } \\
\text { larga } \\
12 \text { furos }\end{array}$ & - & $0^{\circ}$ & $2^{\circ}$ recurvo & $0^{\circ}$ & $2^{\circ}$ \\
\hline 7 & $66^{\circ}$ & $04 / 05 / 2005$ & $\begin{array}{l}\text { Ântero } \\
\text { medial }\end{array}$ & $\begin{array}{c}\text { DCP } \\
8 \text { furos }\end{array}$ & 2 & $8^{\circ}$ varo & $1^{\circ}$ antecurvo & $3^{\circ}$ externo & $8^{\circ}$ \\
\hline 8 & $56^{\circ}$ & $28 / 09 / 2005$ & $\begin{array}{l}\text { Ântero } \\
\text { medial }\end{array}$ & $\begin{array}{c}\text { DCP } \\
7 \text { furos }\end{array}$ & 1 & $4^{\circ}$ varo & $1^{\circ}$ recurvo & $0^{\circ}$ & $4^{\circ}$ \\
\hline 9 & $64^{\circ}$ & $05 / 10 / 2005$ & $\begin{array}{l}\text { Ântero } \\
\text { lateral }\end{array}$ & $\begin{array}{c}\text { DCP } \\
8 \text { furos }\end{array}$ & - & $2^{\circ}$ valgo & $4^{\circ}$ recurvo & $2^{\circ}$ interno & $4^{\circ}$ \\
\hline 10 & $62^{\circ}$ & $09 / 11 / 2005$ & $\begin{array}{l}\text { Ântero } \\
\text { medial }\end{array}$ & $\begin{array}{c}\text { DCP } \\
10 \text { furos }\end{array}$ & 2 & $0^{\circ}$ & $8^{\circ}$ antecurvo & $0^{\circ}$ & $8^{\circ}$ \\
\hline
\end{tabular}

QUADRO 4

Dados das mensurações referentes ao comprimento, tempo de consolidação e complicações da osteotomia no período pré e pós-operatório

\begin{tabular}{|rcccc|}
\hline $\mathbf{N}$ & $\begin{array}{c}\text { Encurtamento } \\
\text { pré (cm) }\end{array}$ & $\begin{array}{c}\text { Encurtamento } \\
\text { pós (cm) }\end{array}$ & $\begin{array}{c}\text { Tempo } \\
\text { consolidação } \\
\text { (semanas) }\end{array}$ & Complicações \\
\hline 1 & 3,0 & 0 & 12 & - \\
2 & 0,5 & 0 & 14 & - \\
3 & 0 & 0 & 16 & celulite \\
4 & 0 & 0 & 16 & reosteossíntese; retarde; infecção tardia \\
5 & 1,25 & 1,0 & 30 & retarde \\
6 & 3,0 & 1,5 & 28 & - \\
7 & 1,0 & 0,5 & 16 & celulite; deiscência; retarde \\
8 & 0,5 & 0,5 & 26 & - \\
9 & 2,5 & 2,5 & 14 & - \\
\hline
\end{tabular}




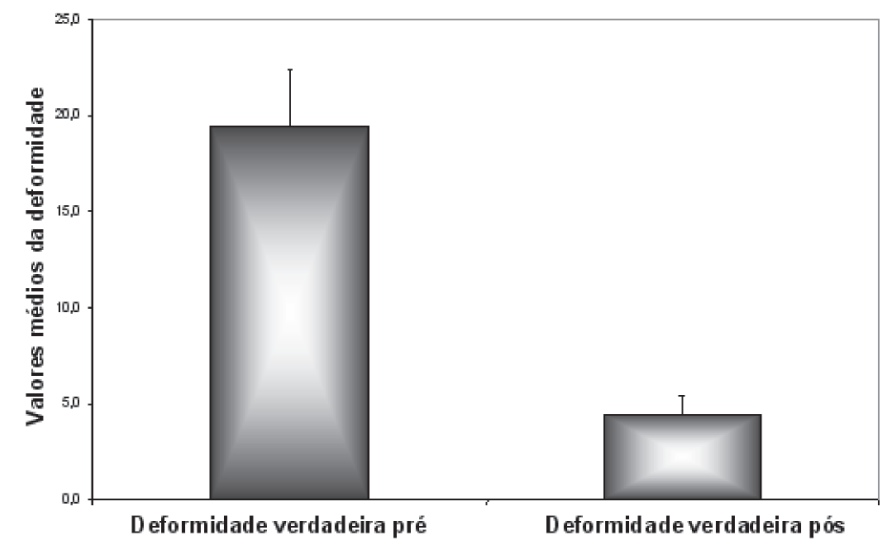

Gráfico 1 - Valores médios do ângulo da deformidade verdadeira e seus respectivos erros padrões

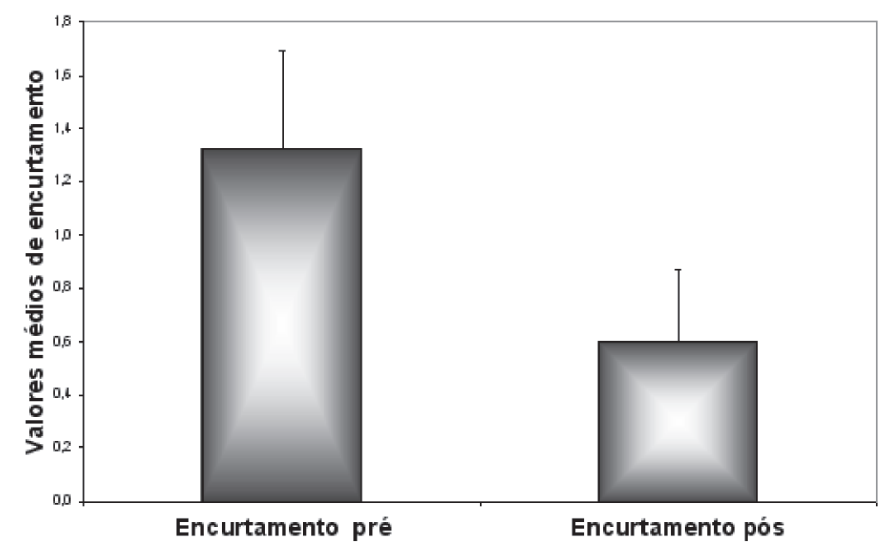

Gráfico 2 - Valores médios do encurtamento do membro e seus respectivos erros padrões

varo, após perda da redução intra-operatória durante a tentativa de obter, em traço de osteotomia quase transverso, compressão interfragmentária com a placa DCP disposta na concavidade da deformidade. Como complicações, além das descritas, tivemos dois retardes de consolidação cujas curas ocorreram com 26 e 28 semanas. Julgamos que tenham sido determinados por necrose óssea, resultado do excessivo aquecimento ósseo criado pelo atrito da lâmina da serra.

Estes resultados estão ilustrados pelos gráficos 1, 2, $3,4 a$ e $4 b$.

\section{DISCUSSÃO}

É controversa a magnitude de deformidade óssea diafisária, que necessita de tratamento. Na tíbia são

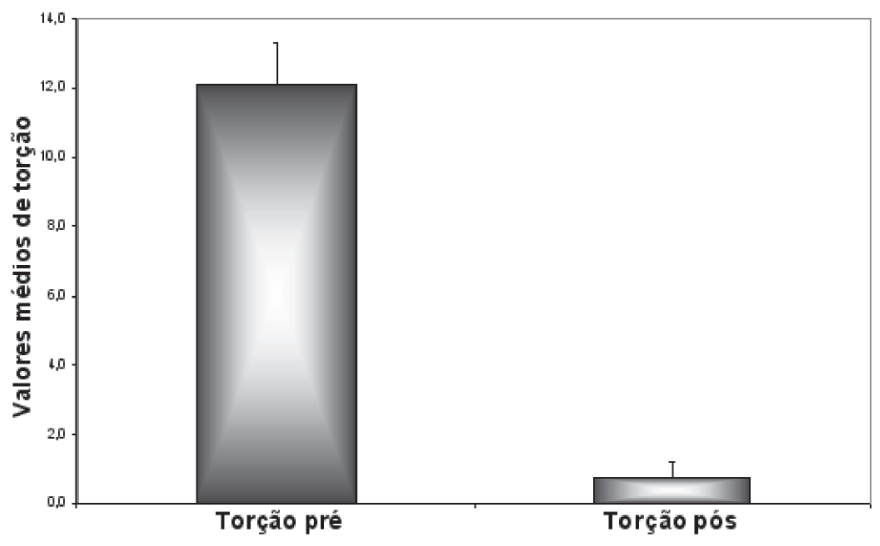

Gráfico 3 - Valores médios da deformidade de torção e seus respectivos erros padrões

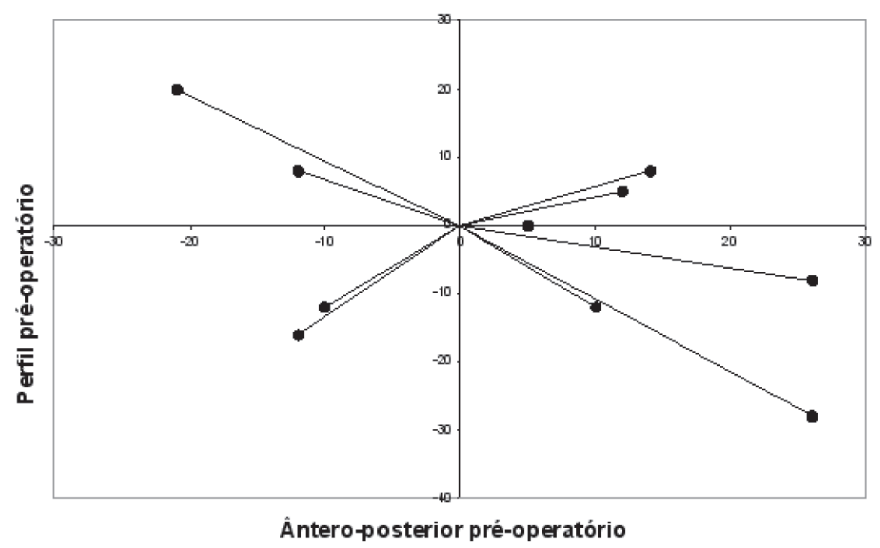

Gráfico 4A - Dispersão entre os valores medidos nas incidências ântero-posterior e perfil pré-operatório para determinação da deformidade verdadeira

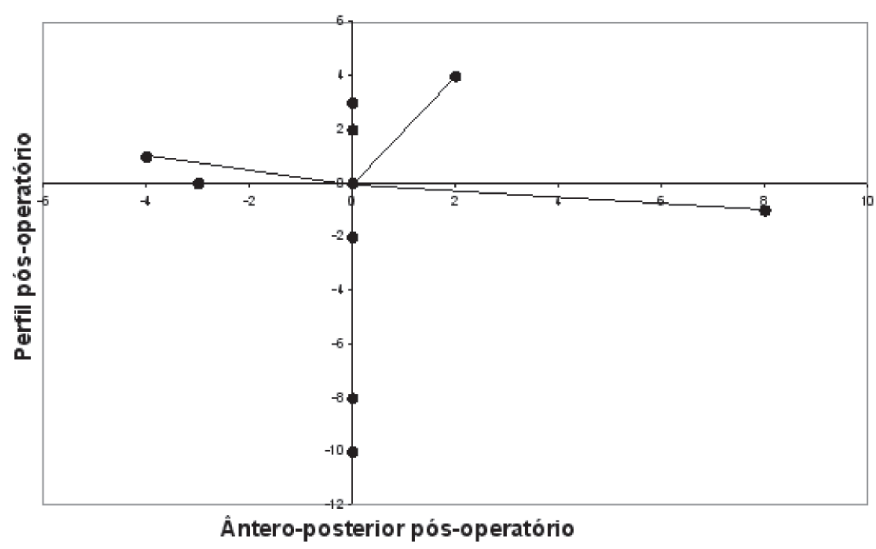

Gráfico 4B - Dispersão entre os valores medidos nas incidências ântero-posterior e perfil pós-operatório para determinação da deformidade verdadeira 
indicadas correções nas deformidades em valgo maior de $12^{\circ}$ e varo maior de $6^{\circ}$; torção externa superior a $15^{\circ}$ e interna superior a $10^{(17)}$. Sanders et al indicam correções nas deformidades iguais ou superiores a 10 graus $^{(18)}$. As deformidades torcionais externas podem ser toleradas até $20^{\circ}$ e internas até $15^{\circ(19)}$.

Em nossa opinião a indicação de osteotomia corretiva para deformidade angular do fêmur e da tíbia não deve basear-se nos valores encontrados nas medidas nos planos anatômicos, mas sim na magnitude da angulação da deformidade verdadeira, que apresenta sempre valor maior ou igual às suas projeções.

Existem várias formas de osteotomias para correção de deformidades ósseas. As osteotomias cupuliformes conseguem corrigir deformidades multiplanares metafisárias, porém são difíceis de serem realizadas na diáfise quando determinam áreas limitadas de contato dos fragmentos osteotomizados, tornando difícil a fixação, acarretando estabilidade precária. As osteotomias lineares transversais só conseguem corrigir o defeito torcional ${ }^{(12)}$. As osteotomias de adição ou subtração de cunhas ósseas são as mais freqüentemente empregadas, sobretudo em regiões metafisárias ${ }^{(12)}$. A primeira acrescenta algum comprimento, porém necessita de osso de área doadora, e a segunda acrescenta encurtamento, na maioria dos pacientes, inaceitável quando somado ao existente. Ambas podem cursar com distúrbios da consolidação óssea ${ }^{(1,18)}$. Consideramos todas estas formas de osteotomias inadequadas para a correção das deformidades complexas e suas necessárias osteossínteses internas. As osteotomias oblíquas são simples e versáteis, podendo ser realizadas no plano sagital para as correções no plano coronal e com retirada suplementar de cunhas consegue-se a correção no plano sagital e da deformidade torcional ${ }^{(10)}$. As osteotomias oblíquas de corte único sem a retirada de cunhas ósseas, baseado no modelo matemático de Sangeorzan ${ }^{(8)}$, são capazes de corrigir a torção e a angulação simultaneamente.

O planejamento para o emprego desta técnica necessita ser preciso. Os planejamentos desenhados nos moldes descritos ${ }^{(9,11,20)}$ são em nossa opinião insuficientes. A construção de modelo tridimensional pro- porciona a compreensão adequada da deformidade e posição do corte ósseo a ser realizado.

Nós desenvolvemos um método que proporciona, além da compreensão, a simulação da correção da deformidade óssea, confirmando a direção do corte a ser realizado, já que há duas possibilidades, ambas corrigirão a angulação, porém uma corrigindo a torção, a outra dobrando o valor de graus na deformidade rotacional.

No modelo podemos antecipar a posição do ápice de deformidade a ser alcançado e sua necessária via de acesso e eventuais obstáculos (fíbula, feixe vasculonervoso). O modelo ósseo estava disponível exclusivamente para o lado direito. Quando a deformidade era do lado esquerdo, construímos modelos direitos com imagens em espelho do lado esquerdo a ser tratado.

Empregamos o método gráfico, menos preciso, para a obtenção da deformidade angular verdadeira, pela sua simplicidade. $\mathrm{O}$ método trigonométrico é exato, o gráfico tem variação de erro até $4^{\circ}$ para todos os ângulos medidos nas radiografias AP e P menores de $45^{\circ}$, sendo de $2^{\circ}$ quando um dos parâmetros angulares é menor de $45^{\circ}$ e outro menor de $20^{\circ(9)}$. Acreditamos ser o método gráfico suficiente, pois a maioria das deformidades angulares a serem corrigidas são menores de $45^{\circ}$.

Para a determinação da deformidade torcional empregamos a avaliação clínica. Os erros originados com este tipo de medida influenciaram na exatidão de determinação do ângulo "Teta". A literatura considera o método de tomografia computadorizada mais preci$\mathrm{so}^{(5-6,11-12)}$.

Outras fontes de imprecisão e dificuldades foram identificadas durante a execução das cirurgias. O ápice de deformidade nem sempre foi acessível pelas vias cirúrgicas habituais. A solução nestas situações foi realizar a osteotomia pela concavidade da deformidade, identificada pela técnica da visão da deformidade de máxima intensidade. A precisão na colocação dos fios K1 e K2 é importante e gabaritos para ângulos, disponíveis no material ortopédico para osteossíntese, são necessários. Outros gabaritos de ângulos diferentes (para o ângulo "Teta") podem ser confeccionados a 
partir de latas de alumínio. Dessa forma, esterilizados, podem amoldar-se à superfície convexa do osso para correta marcação da inclinação da osteotomia. Os goniômetros disponíveis, via de regra são muito grandes e não conseguem ser úteis dentro da incisão cirúrgica.

A realização de osteotomia deve ser com serra oscilatória, de forma completa e sob contínua irrigação para o resfriamento dos extremos ósseos. Cortes incompletos, ou realizados com osteótomos ou por perfurações prévias, são menos precisos e criam superfícies irregulares, prejudicando o adequado contato dos fragmentos ósseos. O controle da redução dos extremos é realizado por radioscopia, mas a correção da rotação é melhor avaliada por comparação ao lado contralateral que deve estar incluso no campo cirúrgico.

Consideramos a fixação interna com hastes intramedulares menos eficientes, pois necessitam de exato alinhamento do canal medular, o qual muitas vezes está obliterado pelo calo ósseo ou fragmentos e parafusos quebrados. A fresagem do canal medular necessária para o uso de haste só pode ser realizado após a correção de deformidade e não permite qualquer ajuste intra-operatório.

A estabilidade absoluta é preferida para a fixação destes tipos de osteotomias ${ }^{(10-11,21)}$. Preferimos a osteossíntese com placa e parafusos de tração. As superfícies de contato entre os fragmentos ósseos após a correção são amplas e com boa adaptação, facilitando a osteossíntese rígida com compressão interfragmentar e placa de neutralização.

Consideramos bons os nossos resultados quanto à correção das deformidades. Nossos pacientes portavam deformidades angulares verdadeiras, com média de $19^{\circ}$; com o tratamento operatório, as deformidades angulares verdadeiras passaram a medir em média $4^{\circ}$. As deformidades torcionais, com média de $12^{\circ}$, foram corrigidas para o valor médio de $1^{\circ}$. A correção absoluta foi obtida em um paciente. Acreditamos que nosso estudo comprove que a técnica de correção da deformidade óssea complexa por osteotomia oblíqua, com corte único, é factível e aplicável na prática clíni$\mathrm{ca}$, levando a resultados satisfatórios. O método apre- sentado sistematiza o planejamento pré-operatório e a técnica cirúrgica, demonstrando com precisão a qualidade dos resultados.

\section{CONCLUSÃO}

O presente estudo mostrou ser possível estabelecer um método confiável e reprodutível para a técnica da osteotomia em plano oblíquo por corte único para a correção de deformidades diafisárias complexas de ossos longos.

\section{REFERÊNCIAS}

1. Sangeorzan BP, Judd RP, Sangeorzan BJ. Mathematical analysis of single-cut osteotomy for complex long bone deformity. J Biomech. 1989;22(11-12):1271-8.

2. Merle d'Aubigné R, Descamps L. L'osteótomie plane oblique dans la correction des déformations des membres. Mem Acad Chir (Paris). 1952;78(8-9):274-6.

3. Frain P, Merle d'Aubigné R. Comment réaliser une ostéotomie plane oblique. Rev Chir Orthop Reparatrice Appar Mot. 1983; 69(6):425-32.

4. Rossi JD, Barr R. Osteotomia subtrocantérica oblíqua: um método para facilitar seu planejamento e execução. Rev Bras Ortop. $1984 ; 19(2): 49-52$.

5. Gürke L, Strecker W, Martinoli S. Korrektur mehrdimensionaler Deformationen durch eine einzige Osteotomie. Graphische Analyse und Operationstechnik. Unfallchirurg. 1999;102(9):684-90.

6. Paccola CAJ. Como planejar osteotomias corretivas para fraturas consolidadas com desvios angular e rotacional, com um único corte de serra. Rev Bras Ortop. 1997;32(6):413-7.

7. Reid JS, Nielsen B, Gilot G, Juliano P, Moran E. The use of the "no angulation view" for single oblique cut: corrective osteotomies of complex tibial malunions. In: 14Th Annual Meeting Trauma Association; 1998. [cited 2004 Nov 18]. Available from:http://www.hwbf.org/ota/am/ota98/otapa/OTA 98304.htm

8. Sangeorzan BJ, Sangeorzan BP, Hansen ST Jr, Judd RP. Mathematically directed single-cut osteotomy for correction of tibial malunion. J Orthop Trauma. 1989;3(4):267-75.

9. Paley D. Oblique plane deformities. In: Paley D. Principles of deformity correction. 2nd ed. Berlin: Springer; 2003. p. 17594.

10. Johnson EE. Multiplane correctional osteotomy of the tibia for diaphyseal malunion. Clin Orthop Relat Res. 1987;(215):22332.

11. Mast JW, Teitge RA, Gowda M. Preoperative planning for the treatment of nonunions and the correction of malunions of the long bones. Orthop Clin North Am. 1990;21(4):693-714. 
12. Keppler P, Suger G, Kinzl L, Strecker W. Korrekturen bei Asymmetrien der unteren Extremität. Chirurg. 2002;73(10): 982-9.

13. Bouchard R, Meeder PJ, Krug F, Libicher M. Bestimmung der Tibiatorsion - Vergleich von klinischen Winkelmessungen zur Computertomographie. Rofo. 2004;176(9):1278-84.

14. Staheli LT, Corbett M, Wyss C, King H. Lower-extremity rotational problems in children. Normal values to guide management. J Bone Joint Surg Am. 1985;67(1):39-47.

15. Perren SM, Frigg R, Hehli M, Tepic S. Parafuso de tração. In: Rüedi TP, Murphy WM, organizadores. Princípios AO do tratamento de fraturas. São Paulo: Artmed Editora; 2002. p. 157-67.

16. Wittner B, Holz U. Placas. In: Rüedi TP, Murphy WM, organizadores. Princípios AO do tratamento de fraturas. São Paulo: Artmed Editora; 2002. p. 157-67.
17. Rosemeyer B, Pförringer W. Basic principles of treatment in pseudarthroses and malunion of fractures of the leg. Arch Orthop Trauma Surg. 1979;95(1-2):57-64.

18. Sanders R, Anglen JO, Mark JB. Oblique osteotomy for the correction of tibial malunion. J Bone Joint Surg Am. 1995; $77(2): 240-6$

19. van der Werken C, Marti RK. Post-traumatic rotational deformity of the lower leg. Injury. 1983;15(1):38-40.

20. Mast JW. Preoperative planning in the surgical correction of tibial nonunions and malunions. Clin Orthop Relat Res. 1983; (178):26-30.

21. Marti RK, Besselaar FP, Raaymakers ELFB. Consolidação viciosa. In: Rüedi TP, Murphy WM, organizadores. Princípios AO do tratamento de fraturas. São Paulo: Artmed Editora; 2002. p. 779-96. 